\title{
Cousins Virtual Jane and Virtual Joe, extraordinary virtual helpers
}

\author{
Seugnet Blignaut ${ }^{\mathrm{a}, *}$, Lynette Nagel ${ }^{\mathrm{b}, 1}$ \\ a North-West University, School for Continuing Teacher Education, Faculty of Educational Sciences, Potchefstroom Campus, Private Bag X6001, Potchefstroom 2520, South Africa \\ ${ }^{\mathrm{b}}$ Department for Education Innovation, University of Pretoria, Pretoria, South Africa
}

\section{A R T I C L E I N F O}

\section{Article history:}

Received 16 May 2008

Received in revised form 3 January 2009

Accepted 5 January 2009

Available online $\mathrm{xxxx}$

\section{Keywords:}

Asynchronous learning

Retention rate

Online facilitation

Virtual communities

Virtual helper

\begin{abstract}
A B S T R A C T
Higher education institutions deliver web-based learning with varied success. The success rate of distributed online courses remains low. Factors such as ineffective course facilitation and insufficient communication contribute to the unfulfilled promises of web-based learning. Students consequently feel unmotivated. Instructor control and in the courseroom further isolates students, whereas success rate increases when students unite in virtual communities. King (2002) increased student participation in his online classes by creating a virtual student, Joe, as a participating student and supplementary facilitator. This investigation responds to King's call for further directions on how a virtual helper enhances online facilitation. This inspired our investigation of how Virtual Jane might augment online facilitation. King's prediction, "It seems that Joe Bags may have a family in the future," (p. 164) became a reality in a South African masters' web-based class on web-based learning.
\end{abstract}

(c) 2009 Elsevier Ltd. All rights reserved.

\section{Background}

The role of the classroom teacher in traditional campus-based education evolved to a common understanding of the skills and competencies essential for successful delivery of higher education (Budin, 1991). However, new skills and competencies should develop as faculty assumes the new role of online facilitator. The reasons for high attrition in campus-based and distributed web-delivered courses differ. Student characteristics like previous grades, age, study environment and personal circumstances profoundly influence success in classroom teaching (Muse, 2003). He found that the "reason given most often for dropout [from web-based courses] was that the student could not obtain, access, or install all the required learning materials in a timely manner" (Muse, 2003, p. 241). Among adult learners, computer self-efficacy is associated with satisfaction in web-based learning (Liu, Lee, Bonk, Su, \& Magjuka, 2005). Swan found that success in webbased courses depended on only three factors, namely "consistency in course design, interaction with course instructors, and active discussion" (Swan, Shea, Fredericksen, Pickett, \& Pelz, 2000, p. 513). After course design and computer competency have been optimized, the technology becomes transparent, and then the nature of the interaction with instructors and the active discussion involving peers become the factors determining successful studies.

Online facilitators must now understand the nature and psychology of online education, identify the characteristics of distributed learners and design technology-based courseware, and adapt their teaching strategies to deliver instruction online (Trollip \& Blignaut, 2003). Reeves (2002) calls for “... scholarship of teaching intended to optimize the roles of human teachers and digital technologies in tertiary education."

Distributed online education suffers from difficulties. It must address the low success rate (King, 2002), determine the ideal class size (Tomei, 2006), assess the impact of electronic learning on faculty teaching loads (Blignaut \& Trollip, 2005), examine the role of online facilitators and their contribution in the courseroom (Collison, Elbaum, Haavind, \& Tinker, 2000), and assess learning outcomes across the internet (Reeves, 2002). Online education must also address the different roles of the facilitator (Anderson, Rourke, Garrison, \& Archer, 2001) and the effects of insufficient faculty development for online facilitation (Blignaut \& Trollip, 2003b). Despite these concerns, students are lured to online higher educational courses with promises of personal conveniences such as anytime, anywhere and just-for-me education. As a result, novices may suffer isolation from peers, frustration with technology, anxiety over failure, and confusion with navigating the online courseroom. These experiences lead to incomplete courses - up to fifty percent more than in traditional campus education (King,

\footnotetext{
* Corresponding author. Tel.: +27 18299 4566; fax: +27 182994558.

E-mail addresses: seugnet.blignaut@nwu.ac.za, seugnet@iburst.co.za (S. Blignaut), Lynette.Nagel@up.ac.za (L. Nagel).

1 Tel.: +27 124202131 .
} 
2002). Students new to asynchronous online education should receive special support to ameliorate their fear of inadequacy, isolation and poor motivation.

The ways in which online facilitators conceptualize their online presence contribute to students' disconnection from peers and support. Current literature refers to online facilitators" involvement and visibility in online classes in subjective terms such as "guide on the side" (Collison et al., 2000), "sage on the stage" (Coppola, Hiltz, \& Rotter, 2002), "ghost in the wings" (Mazzolini \& Maddison, 2003), and "mentor in the middle" (Collison et al., 2000). These concepts embrace the basic epistemology of online facilitators' mental models of online facilitation. Regrettably, many online facilitators do not budge from their positivist stance and wish to remain kingpin in their courses. Various authors (Collison et al., 2000; Dutton, Dutton, \& Perry, 2002) believe that an autocratic and manipulative approach to computer-mediated communication (CMC) contributes to learners' isolation in a learning environment that, in order to succeed, should ideally build upon social constructivist learning principles. In constructivist learning environments, it is therefore vital that online facilitators maintain a suitably low profile and not dominate the courseroom, as domination stifles student participation (Berge, 1995; Collison et al., 2000).

The way a facilitator scaffolds an online class differs markedly from a contact classroom setting. The Collison (2000, p. xvi) model of Guide on the Side displays the following characteristics: humility; the capacity to listen (read) and respond without interjecting personal or professional opinions, practice online wait time, allow students to reflect extensively (even for days), as well as afford rich thinking and redirection of debates. The first four characteristics present an attitude of calculated restraint that supports the guide on the side role of facilitation, rather than of direction. Online facilitators encounter numerous challenges and the range of required competencies often extends beyond the capacity of a single person.

Berge (1995) lists the four roles for online instructors as pedagogical, social, managerial and technical. While some prefer a holistic pedagogical approach, others argue strongly for the promotion of the social aspects of online learning (Salmon, 2003; Wegerif, 1998). Liu et al. (2005) explored instructors' challenges when attempting to fulfill the four roles defined by Berge and concluded that they succeeded therein to varying degrees, mostly with more emphasis on the pedagogical roles. While online instructors prefer some of the facilitator roles, they often neglect others (Liu et al., 2005).

Assuming that all four roles of a facilitator are important, the same person need not carry out all of them (Berge, 1995); neither need all online scaffolding be the sole responsibility of the facilitator. In an online class, students often represent an untapped resource (Stafford, 2008). The teaching role of a peer student is not only valuable but also necessary for integration of students into the learning community where peers should support and learn from each other (Collison et al., 2000; Wegerif, 1998). The "individual success or failure in a course depended upon the extent to which students were able to cross a threshold from feeling like outsiders to feeling like insiders" (Wegerif, 1998, p. 34). An online facilitator has to nurture the establishment of the online community carefully. Well-functioning online communities require that:

- participants post regularly

- the online community meets its members' needs, and participants express honest opinions

- participants collaborate and spontaneous moderating occurs among the participants

- participants vent about technology, content, and even the facilitator

- participants support their community (Collison et al., 2000).

Facilitators can in some circumstances slow down the progress of students, especially when students perform complex tasks poorly and when students perceive that they were being watched by either a real or virtual spectator. They do not want to look incompetent (Zanbaka, Ulinski, Goolkasian, \& Hodges, 2007). According to Cottrell, Wack, Sekerak, and Rittle (1968) poor performance is due to evaluation apprehension when performing tasks in front of an audience. This apprehensive human-human interaction carries over to the online world where interface agents and humans meet.

In order to alleviate tedious aspects of online facilitation, education sees the emergence of more online agents to support web-based learning. Gulz proposes that the addition of virtual characters to a learning environment has potential pedagogical benefits, like "increased motivation, stimulation of particular learning activities, enhanced flow of communication and fulfillment of a need for deeper personal relationships in learning" (Gulz, 2004, p. 313). Mostly, virtual agents' function in a virtual classroom seldom extends beyond assisting with the organization of learning content and helping with searches. These agents act inter alia as user guides, personal information managing assistants, architectural solutions, alternative help systems and for simulation in virtual environments, information seekers, planning agents (Aroyo \& Kommers, 1999). Four principles define their behavior: autonomy, responsiveness, pro-activeness and social ability. When students receive personalized messages from an agent, they "performed better on retention and problem-solving transfer tests" (Moreno \& Mayer, 2004, p. 165). Agents' functions seem to overlap with an online facilitator's tasks, as students require both content-based and affective feedback. Finding the best way to use agents to enhance learning suggests that their designers take note of the crucial dimensions of facilitator interaction.

We encountered King (2002) in our search for effective web tools to ameliorate our online students' detachment from support. He bases his success in graduate-level asynchronous online courses on establishing, nourishing and growing student virtual learning communities. He creates a fictitious virtual student to participate in discussions and team assignments in order to increase student participation: "Accordingly, I have used Joe to get the discussion started and to get him involved with the other students as an equal member of the class, thereby forming a sense of community as early as possible" (p. 162). Virtual Joe's online persona reflects the voices of Collison et al. (2000): generative guide, reflective guide, personal muse and mediator. Although the students in King's courses knew Joe was fictitious, they responded to him as if he were a real student (King, 2002; Reeves \& Nass, 1996).

\section{Context of the study}

Twenty-three students at the University of Pretoria enrolled for an eight-week masters' level course on web-based learning via the internet. Eighteen female and five male students enrolled in the class. Nine students were black; fourteen were teachers; five worked in e-learning companies and four at higher education institutions. Their ages ranged from thirty to fifty. Computer viruses, work-related 
issues, and poor access to the Internet caused three students to withdraw during the initial weeks. Twenty students completed the course, and two failed. One of the students who completed the course was a fictitious student and facilitator assistant, Virtual Jane Malan.

Jane, who was an additional log-in of the course facilitator, mirrored the gender of the facilitator to ensure that she would not commit gender-based oversights addressing her peers. To match the demographic characteristics of the cohort, Jane's indistinct picture in the courseroom revealed a mixed race person, thirty-something, working at a computer. She introduced herself saying, "My name is Jane, and I am a relief teacher, having taught countless subjects. Computers are a hobby, keeping me busy between jobs and helping my partner in his small business." Jane explained to her peers that she "lived far away" and could not attend the end-of-course get-together. Our premise was that if the cohort trusted Jane and accepted her into the virtual learning community; it would demonstrate virtual learning's capacity to accommodate foreign and isolated students.

We modeled Jane's role on the new kid on the block who wanted to become the students' friend, confidante and stirrer in the class to elicit discussion. Virtual Jane and Joe shared characteristics. They provided their classes with two facilitators, they supported collaborative learning as well as social construction of learning, and they completed all assignments and online discussions. Virtual Jane and Joe targeted student questions and responded according to "their experience." Neither dominated the courseroom and only provided feedback when called upon, to prevent one-way, instructor-dominated communication (King, 2002). They both favored deliberate instead of reactive facilitation.

As Virtual Jane was not the "teachers' pet," she had to earn credibility from her peers. Since "computers were her hobby," she willingly shared her competence with the class. In this respect, she assumed facilitator functions and responsibilities in the virtual learning community. The most obvious difference between our fictitious student, Jane Malan, and King's Joe Bags O'Donuts was that we did not disclose her identity to the class either before or during the course. Virtual Jane's identity remained hidden until the end of the investigation. Only at the end of the course did we disclose her virtual identity to the class via an e-mail. This revelation provided students an opportunity to reflect on Jane's role in the courseroom and her secret identity. These aspects are published elsewhere (Nagel \& Blignaut, 2008; Nagel, Blignaut, \& Cronjé, 2007).

Ethical aspects surrounded Jane's undisclosed persona. Some may object to her undisclosed identity as it "may undermine their selfrespect, their psychological integrity, their sense of self-determination, or even their physical health" (Boeree, 1998). In this regard, Piaget refers to "la méthode clinique," a situation in which a phenomenon occurs irregularly. Garfinkel extended Piaget's methods and invented the concept of participant observation. Jane filled the role of participative observer in the asynchronous courseroom. We did not manipulate the students' behavior, but carefully observed them in a contrived setting. The students gave consent that all CMC would be analyzed as part of ongoing research with which they were familiar. In order to comply with ethical research guidelines, we disclosed Jane's real identity after completion of the course and debriefed the students. As part of ethical concerns of undisclosed participation, we published our findings for the benefit of others intending to employ similar interventions. Students' reactions following the disclosure of this virtual student were mostly positive, as they realized that Jane brought them no harm. In fact, she made unique contributions to the class (Nagel et al., 2007). One student wrote: "I don't think she harmed the learning process at all and she assisted students who are not confident enough to participate more."

\section{Research questions}

As part of our ongoing research on the role of the online facilitator in asynchronous classes, and in response to King (2002) call for further directions on using a virtual helper to further virtual learning communities, we focused on the following questions for our investigation:

1. How did Virtual Jane contribute to the facilitation of an asynchronous online course?

2. How did Jane's facilitator style differ from the course facilitator's?

3. What were the practical implications for future courses?

\section{Methodology}

The course was available through the WebCT ${ }^{\mathrm{m}}$ Campus Edition 4.0-platform. The students and facilitator posted communication to the formal asynchronous courseroom's discussions area and to an informal non-topic conversation area. The students also posted assignments to the courseroom. The facilitator did not aim to control the flow of asynchronous discussion through deliberately withholding replies to students' postings, allowing peers the first opportunity to respond (Mazzolini \& Maddison, 2003). The course facilitator only intervened when solutions were imperative. In contrast, we modeled Virtual Jane as a fully participating student, supporting others with contextual and technical problems when peers did not provide sufficient feedback to address a specific problem.

For analysis of the data, we captured all the CMC of the facilitator and Virtual Jane in the course room for the duration of the course. These asynchronous course postings constituted the unit of analysis for this investigation. We followed a qualitative approach to data analysis and used the Atlas.ti ${ }^{\mathrm{TM}}$ computer-based qualitative analysis program for a deductive approach to content analysis and coding of the integrated dataset.

In a previous phase of the ongoing research on the role of the online facilitator, Blignaut and Trollip (2003a) followed a basic contentanalysis methodology to classify instructor postings according to thematic messages (Anderson et al., 2001) and developed a six-category taxonomy of online facilitator interactions. A listing of the six categories, as well as descriptions and examples of the categories appears in Table 1.

The underlying thematic approach to analysis and coding enabled us to capture the essence of each posting. More than one code can be assigned to a single posting, and a posting may contain more than one theme (messages) that relate to one or more categories of the taxonomy (Blignaut \& Trollip, 2003a). For example: It was very insightful of you (affective message) to tie the development of storyboards to both team communication and project management (informative message). The approach proved advantageous, as all facilitator postings did not 
Table 1

Taxonomy of facilitator interactions (Blignaut \& Trollip, 2003a).

\begin{tabular}{|c|c|}
\hline Category & Description and example \\
\hline $\begin{array}{l}\text { Administrative (with no academic } \\
\text { content) }\end{array}$ & $\begin{array}{l}\text { Postings that relate to general administrative topics such as dates, profiles, formats, functionality of software and many other } \\
\text { organizational aspects, e.g.: } \\
\text { Welcome to the class! I have recorded your preference for a letter grade. I look forward to your contributions to the class. }\end{array}$ \\
\hline $\begin{array}{l}\text { Affective (with no academic } \\
\text { content) }\end{array}$ & $\begin{array}{l}\text { Postings that acknowledge learner participation and provide affective support, e.g.: } \\
\text { I am enjoying your comments and especially the replies and threads that are forming. Keep up the great work! }\end{array}$ \\
\hline Other (with no academic content) & $\begin{array}{l}\text { Postings that contain non content-related messages, as well as the posting of discussion topics, e.g.: } \\
\text { - Here's the official wording! Discussion 2: Is consciousness at the heart of psychology or is it a concept outside the realm of psychology? } \\
\text { Support your responses with references. } \\
\text { - To all the mothers in the class, a Mother's Day card ... }\end{array}$ \\
\hline Corrective (with academic content) & $\begin{array}{l}\text { Postings that correct the content of a learner's postings, e.g.: } \\
\text { You have talked about the instructional designer not being the project manager, however; you have listed several project management } \\
\text { duties, e.g. under \# } 7 \text { to monitor: time spend, ... Please reconsider if these are project manager duties or ... }\end{array}$ \\
\hline $\begin{array}{l}\text { Informative (with academic } \\
\text { content) }\end{array}$ & $\begin{array}{l}\text { Postings that comment on a learner's posting from a content perspective and provides individual feedback, e.g.: } \\
\text { This is a fine posting, not only answering the question but going into reflection and application of your experience to an attempt to solve the } \\
\text { problem. In addition, while you took your own position based on your experience, you posed a counter argument, which is the essence of } \\
\text { scholarly discussion. You make a fine example of good intellectual discourse, by raising the contrary arguments and treating them } \\
\text { respectfully. Nicely done! }\end{array}$ \\
\hline Socratic (with academic content) & $\begin{array}{l}\text { Postings that ask reflective questions (Socratic questions) about the learner's postings, e.g.: } \\
\text { In your posting you took the position of a teacher. Please explain the same scenario from the position of a learner. }\end{array}$ \\
\hline
\end{tabular}

necessarily focus on only one central idea, and it aimed to capture both the quantity and quality of facilitator interaction. In their study, Blignaut and Trollip (2003a) established an inter-rater reliability of 0.890 and an intra-rater reliability of 0.985 using Cohen's Kappa procedure.

The first author used this Blignaut and Trollip taxonomy to deductively analyze and code the dataset of combined facilitator participation in the courseroom. The second author and main facilitator of the course performed member checks on the coding. Inter-rater and intra-rater scores were 0.910 and 0.932 , respectively and well within the acceptable range of above 0.75 (Anderson et al., 2001 ).

\section{Findings}

\subsection{Virtual Jane's Contribution to the facilitation of an asynchronous online course}

The dataset contained 247 facilitator discussion postings, eight extensive facilitator's weekly summative postings on the learning units, and 54 postings from Virtual Jane. We therefore considered a total of 309 postings for this analysis. The total CMC in the courseroom comprised 1623 postings. This indicates that while the facilitator contributed $15.71 \%$ of the posts, Virtual Jane contributed $3.32 \%$ of the total. This $19 \%$ total facilitation contribution lies well within the boundaries that Jonassen, Davidson, Collins, Campbell, and Haag (1995) introduced and King (2002) subscribed to. Virtual Jane posted 111 messages; the combined facilitators contributed 583 messages. Fig. 1 compares the courseroom contributions of the facilitator and Virtual Jane in terms of the six categories of the taxonomy of facilitator interactions (Blignaut \& Trollip, 2003a).

At first glance it seems as if Virtual Jane contributed little and that her contributions mainly related to affective and informative interactions with her peers. It also reveals that the facilitator was often tied up with course administrative issues, while Virtual Jane generally kept clear of such involvement. However, when we expressed Virtual Jane's and the facilitator's contributions as a percentage of their total contribution, new insights emerged (Fig. 2). This figure illustrates that Virtual Jane's contributions relating to messages without academic content (other, administrative and affective messages) are the same or lower than the facilitator's contribution, while her messages with academic content (corrective, Socratic and informative messages) are consistently higher.

Next we will discuss Virtual Jane's participation in the courseroom as illustrated in Fig. 2 in terms of each of the six categories of facilitator interaction (Blignaut \& Trollip, 2003a) and effective strategies for online facilitation (Collison et al., 2000). We provide representative examples of messages in each category.

\subsubsection{Other messages}

This category contains non-content related contributions and refers to social dialogue in the courseroom (Collison et al., 2000, p. 20). Although this category is necessary in online communication to set an informal, welcoming tone, many believe that it should be used sparingly and deliberately as too many messages of this type clutter the courseroom (Blignaut \& Trollip, 2003b) and make navigation between

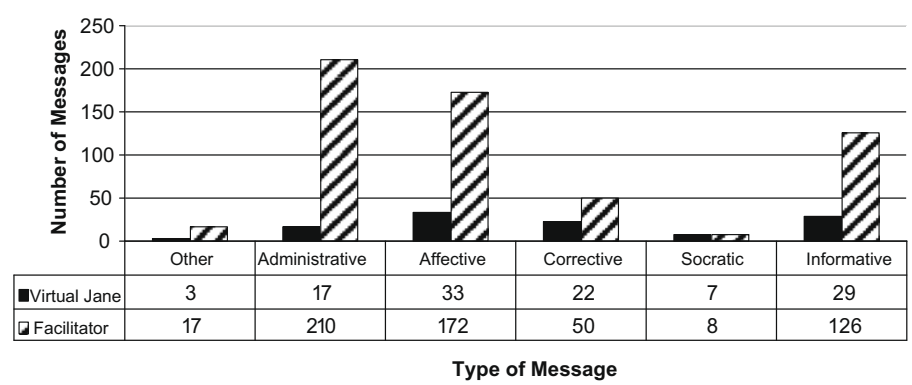

Fig. 1. Actual course facilitation interactions of Virtual Jane and the facilitator. 


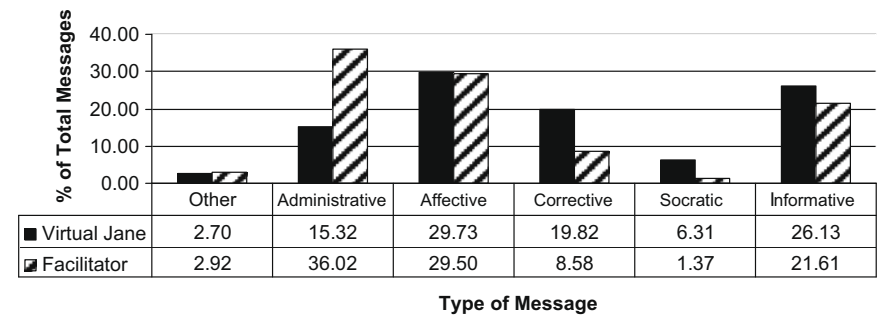

Fig. 2. Course facilitation interactions of Virtual Jane and the facilitator in terms of percentage of messages.

postings difficult when, as in this case, courses contain many student and facilitator contributions. In Virtual Jane's case, she only posted three other messages, and they all reflected her role as a virtual student:

Computers are a hobby, keeping me busy between jobs and helping my partner in his small business.

I was in too much of a hurry last night to properly check my references before I posted.

What a pity I live too far away to attend. Maybe the facilitator can web cast the proceedings from a video cam then we can all join in the fun?

\subsubsection{Administrative messages}

Administrative messages refer to course administrative issues such as deadlines, assignment formats, technical issues and other incidental organizational matters. At first, it seemed as if Virtual Jane was not intensively involved with academic course administration (Fig. 1). However, Fig. 2 indicates that proportionally she contributed about fifty percent of all administrative messages. Receiving such messages from a peer contributes to social communication and collaboration among students. Students consequently do not lose face when requesting the facilitator's technical help when peer support is available. In her capacity as technical advisor, Virtual Jane's contribution as a web-based support tool to assist digitally challenged students became exceptionally important. The first example illustrates Virtual Jane's conceptual facilitating voice when she addresses omissions, confusions and imbalances (Collison et al., 2000, p. 108):

In order to keep the communication as close to reality as possible and to allow participants' real personality to shine through, one should be allowed to use non-academic/informal language, humor etc. An informal approach will encourage students to venture more freely and not be intimidated by everybody else, especially if they are a bit unsure.

The next quote provides evidence of Virtual Jane's facilitation competence as muse in personal dialogue about central issues (Collison et al., 2000, p. 112). Virtual Jane draws on her background to establish credibility with her peers:

Please excuse my ignorance, but I am unable to find the final version of the pointers in this debate. Assuming that the conversation is still ongoing, some thoughts from my side: After many years of teaching and assessing ...

"The reflective guide restates, with slightly different emphasis, the elements of a message. Facilitators using this approach should use a tone and style similar to that of the participants' posting and incorporate more precise language than found in the original posting" (Collison et al., 2000, p. 112). In this message, Virtual Jane clearly sides with the students, yet also provides technical assistance on citation technique within the social cooperative learning context. An example of her reflective facilitation voice:

As I understand it, we only have to fix the mistakes we made in the last round of postings and send them again (to this topic) I can see clearly where my own mistakes are, it should be easy to fix. My opponent did show me what I did wrong the previous round, but I did not remember all of it ...

\subsubsection{Affective messages}

Affective messages refer to messages void of academic content intending to support or encourage students, acknowledgment of student participation, and provide affective support or apology (Blignaut \& Trollip, 2003b). Fig. 2 indicates that Virtual Jane and the facilitator contributed the same proportion of affective messages (29\% of total number of messages) to the courseroom. This is hardly a surprise as Virtual Jane's persona was modeled on the persona of the facilitator! The examples below provide evidence of Virtual Jane's support, validation and commitment to others:

Please do not give up because things are hard. My friend, who did this module two years ago, has never in her life experienced a steeper learning curve in any six weeks. And that whole class survived, they said, and said it was worth it. Hope this helps a little.

You two have been fantastic and really worked so hard at this. My congratulations and thanks.

It seems that we are just forced to do some corrections before going on. I am also glad we are not picked out before everybody else. Sorry about this.

\subsubsection{Corrective messages}

Corrective messages, with academic content, report on postings of a remedial nature, or the redirection of postings back to learners to clear up their misconceptions or to provide corrections (Blignaut \& Trollip, 2003b). Fig. 2 indicates that Virtual Jane proportionately 
provided twice as many corrective postings to the courseroom as the facilitator. Some faculty do not agree with using this type of posting as they argue that adults do not feel comfortable when they may be corrected and that such postings may lead to procrastination (Blignaut \& Trollip, 2003b). However, erring is part of learning, and when correction comes from a peer instead of the instructor, the blow may be less severe. Collison et al. (2000, p. 108) refer to the conceptual voice of the facilitator, including juxtaposing views to encourage deeper dialogue.

The taxonomy for facilitation participation (Blignaut \& Trollip, 2003a), assigns an administrative code to facilitators' messages of technical nature. In developing contexts students experience overwhelming technical problems, and during online courses (Muse, 2003) our students thought the course highly technical. Therefore, we coded the many responses to questions of technical nature as a content-related matter, and these supportive messages we classified as corrective messages. It was in these cases Jane that walked the extra mile to provide effective technical support. Virtual Jane's persona demanded that she not be the "teacher's pet," and occasionally she corrected the facilitator as well as her peers. The first two examples provide evidence of Virtual Jane correcting the facilitator and the next two of student remediation:

On behalf of myself and possibly others who battled to get into Hagar, please note that there is a spelling mistake in the URL, (if you tried to copy and paste it). It should read: http://hagar.up.ac.za/catts/rgb_resources/learner/-<yoursurname>.

This posting of yours is in my opinion totally inappropriate in this place. How is this student supposed to feel? The facilitator is not supposed to be so harsh on students who make mistakes. I thought we are bound by a code of conduct to be tolerant of mistakes and to do unto other ... A very disappointed Jane :-(

I think an important aspect to look at with formal postings is using correct grammar and spelling. Let's not spell like Americans with z's all over the show!

This citation could be moved to the end of the quote, as the repetition of authors is a bit clumsy. It is quite correct to give the page number when quoting directly.

\subsubsection{Socratic messages}

Coppola et al. (2002) reports an overall increase in the Socratic approach to facilitation when instructors switch to virtual professors. Socratic pedagogy refers to the give and take between facilitator and student with questions leading to learning. The instructor shifts from conveying information to raising questions and encouraging dialogue. Messages of a Socratic nature contain academic content and aim to encourage deeper thinking. Proportionally Virtual Jane contributed about four times more Socratic messages than the facilitator (Fig. 2). She directed these messages to the students as part of her role as assistant facilitator.

I am glad for the emphasis on language issues. One thing worries me a bit. How do we consolidate British / SA English with APA style? The latter being the guidelines laid down by the American Psychology Association? Are we being trained for publishing in American Journals only? Maybe one of the Information specialists in the class can help answer this one. I see the prescription of APA style as an example of Globalisation, as it kills other forms of English other than American in academic writing. (This is one of my pet topics!)

Does ... [sic] not considerably overlap with the topic of one of the other groups (cannot remember which) on collaborative behavior? How do the other Wuwuzela's see it? Attached is a tentative list of criteria with some indicators. Surely far from looking like a rubric ...

\subsubsection{Informative messages}

Students crave detailed feedback from their facilitators. Low faculty participation in students' assignments frustrates learners in both traditional campus-based as well as in facilitated online higher education (Hara \& Kling, 2000). However, within a social constructivist model of course facilitation, facilitators aim to postpone their contribution on assignment feedback deliberately to allow peers to react to primary postings. This type of course design therefore calls for additional measures to ensure that students do not become unmotivated, or feel lonely or inadequate due to low course responsiveness. Virtual Jane played an important role here as she contributed 29 informative messages to various students, while the facilitator contributed 126 (Fig. 1). However, Fig. 2 indicates that Virtual Jane proportionally contributed slightly more informative messages to the courseroom. This aspect again reflects her supplementary facilitative role. The evidence reflects Virtual Jane's commitment to deliberate feedback to her peers and illustrates her voice as generative guide (Collison et al., 2000, p. 106):

After many years of teaching and assessing kids' work, I see formative assessment as part of a process where a learner can expect an interim appraisal of his work coupled with constructive comments that will enable him to better his work in future. Using some form of mark or scale makes it easier for him to measure his progress. Summative assessment is final and does not allow remediation. One can go either of two ways in assessment: where one uses a point scale merely as symbols to signify various levels of mastery of the material: my own abridged version of OBE: ... [sic] The problem with this is that no two people will necessarily give the same verdict.

So, burning the midnight oil, I distilled some criteria from the literature on quality (isn't that what rubrics are about?) of student support. Seems you and I look from different perspectives. I see this rubric as assessing what an online course has to offer in the line of support to the student enrolled for it. From what I read in your rubric, it is assessing the behavior of a student in a course, supporting his co-students.

\subsection{The effort to maintain Virtual Jane}

Is it worth the effort to maintain the online persona of Virtual Jane, compile course assignments, contribute to courseroom discussions and react to peers' assignments while simultaneously doubling as a real course facilitator? This is a valid question as more evidence reveals the effort of online facilitators (Blignaut \& Trollip, 2005; Conceição-Runlee, 2001; Coppola et al., 2002; Woods, 2002). Also, various studies report on students' grievances over the low courseroom presence of online facilitators (Fulford \& Zhang, 1993; Hara \& Kling, 2000; Hong, 2002; Prisbell, 1994; Richardson, 2003). 
While Virtual Jane contributed 54 original posts to the courseroom, the other nineteen students averaged 69 postings. In the end-ofcourse evaluation, many students mentioned the high demands of the course in terms of both time and effort. This suggests that, despite her philosophy of deliberate restraint in posting to the courseroom, the facilitator had a hard time keeping up with a double life. King (2002) also comments on the tedious aspects of maintaining his virtual student. As the number of postings grows exponentially with class size, and even though students critique each other, larger cohorts demand extensive reading and typing time from online facilitators (Blignaut \& Trollip, 2005; DiBiase, 2000).

\subsection{Implications for future courses}

This investigation showed that effective facilitation to students can come from different online personae. One may argue that, in order to promote the formation of a virtual community of learners, a significant portion of the facilitation should emanate from student ranks and not visibly from the course facilitator. If employing a virtual helper, this persona can just as well be another person. One of the students remarked:

"I think that it is ingenious and clever, and it has got me thinking about the plausibility of inventing a "ghost" learner for my normal live classes. How could I use such a "ghost" to enhance learning and participation in a responsible manner?"

Taking into account the different roles of a facilitator, purposeful division of tasks and roles will ease the burden of the facilitator, who can sometimes act in a consulting capacity.

\section{Conclusions}

Our investigation responds to King's (2002) call for further research on using a virtual helper in an asynchronous online course. He invited investigation on how students perceived this fictitious student, whether Joe enhanced the students' online educational experience, and how much effort went into maintaining a fictitious student. What are the implications for future courses? We added an additional question: What are the ethical issues of using an undisclosed virtual helper in an asynchronous online course? This paper responds to the umbrella question by asking, what was Virtual Jane's contribution to the facilitation of an asynchronous online course?

We followed a basic qualitative methodology of content analysis according to a thematic approach to qualify and quantify the CMC of the facilitator and her virtual helper, Jane, in a post-graduate level course on web-based learning. We deductively analyzed and coded the dataset of Virtual Jane's and the facilitator's postings according to the Blignaut and Trollip (2003a) taxonomy of facilitator interaction. We observed that, despite being posted by the same person, the facilitator and Jane represented different profiles of facilitating messages to the courseroom. We determined that the three message types without any academic content (other, administrative and affective messages) related to Virtual Jane's role as participative student in the courseroom, and the three message types containing academic content (corrective, Socratic and informative messages) related mainly to her role as supplementary facilitator. The implication that Jane contributed academic messages, particularly correcting and redirecting peers, is that in this capacity she modeled the sought-after behavior of students in a virtual learning community. Because the correction did not visibly originate from the facilitator, it was intended that students not take offence or experience anxiety over their mistakes. Virtual Jane also posted corrective messages to the facilitator, another behavior characteristic of the virtual learning community. She became the students' friend and confidante as she provided both technical and contextual support, elicited discussion, and poured oil on troubled waters. We cannot directly connect the presence of Virtual Jane in the courseroom with the $89 \%$ success rate of this particular course. However, Jane was a valuable helper who provided additional support to learners without increasing the facilitator's domination in the courseroom. In her facilitation Virtual Jane used the voices of conceptual facilitator, generative guide, personal muse, reflective guide and mediator (Collison et al., 2000).

While this paper responds to one of the issues King (2002) placed on the table, our ongoing research on the role of online facilitators aims to address the outstanding issues of students perceptions of the undisclosed student (Nagel \& Blignaut, 2008) and its ethical concerns (Nagel et al., 2007). We do not recommend that a single facilitator with an online class of approximately twenty students double as a virtual student. Although it was a worthwhile experience to live among students in a virtual learning community ("garfinkling") (Boeree, 1998), this type of research should be repeated when a team of real tutors and facilitators can support the main facilitator. Designers can programme some of the predictable tasks for delivery by an online agent. In order to cover the whole spectrum of facilitator tasks, the supporting facilitator(s) and/or agents can focus on specific pre-arranged online facilitator roles. This study can guide which attributes could feasibly separate among different facilitators or agents. Also, as Reeves, Herrington, and Oliver (2005) and King (2002) pointed out, real students react positively to support even when they know that the support is a web-based tool and not a real person. As one student remarked:

What's the difference between a parametric test that responds to your answers and a "person" responding to your activity in a distance learning environment?

\section{References}

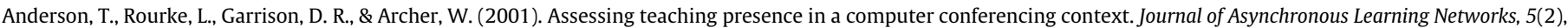
$1-17$.

Aroyo, L., \& Kommers, P. (1999). Special issue preface: Intelligent agents for educational computer-aided systems. Journal of Interactive Learning Research, 10(3/4). Berge, Z. L. (1995). Facilitating computer conferencing: Recommendations from the field. Educational Technology, 35(1), 22-30.

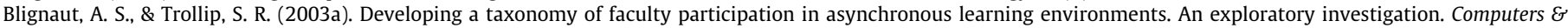
Education, 41(2), 149-172.

Blignaut, A. S., \& Trollip, S. R. (2003b). Measuring faculty participation in asynchronous discussion forums. Journal of Education for Business, 78(6), 347-353.

Blignaut, A. S. \& Trollip, S. R. (2005). Between a rock and a hard place. Faculty participation in online classrooms. Education Change, 9(2), 5-23.

Boeree, C. G. (1998). The qualitative methods workbook. <http://www.ship.edu/cgboeree/qualmethone.html>. Retrieved 10.7.2004.

Budin, H. R. (1991). Technology and the teacher's role. Computers in the Schools, 8, 15-25.

Collison, G., Elbaum, B., Haavind, S., \& Tinker, R. (2000). Facilitating online learning. In W. I. Madison (Ed.). Effective strategies for moderators. Atwood Publishing. 
Conceição-Runlee, S. (2001). Faculty lived experiences in the online environment. Unpublished PhD, University of Wisconsin-Madison, Madison, WI.

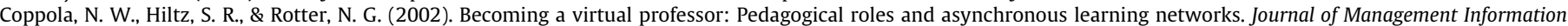
Systems, 18(4), 169-189.

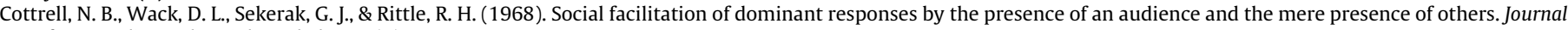
of Personality and Social Psychology, 9(3), 245-250.

DiBiase, D. (2000). Is distance learning more or less work? American Journal of Distance Education, 14(3), 6-20.

Dutton, J., Dutton, M., \& Perry, J. (2002). How do online students differ from lecture students? Journal of Asynchronous Learning Networks, 6(1), 1-20.

Fulford, C. P., \& Zhang, S. (1993). Perceptions of interaction: The critical predictor in distance education. American Journal of Distance Education, 7(3), 8-21.

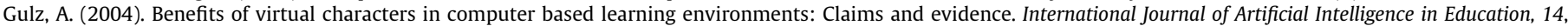
313-334.

Hara, N., \& Kling, R. (2000). Students' distress with a web-based distance education course. Information, Communication E' Society, 3(4), 557-579.

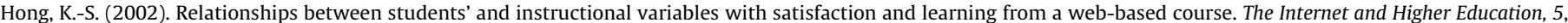
267-281.

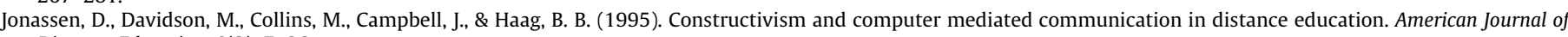
Distance Education, 9(2), 7-26.

King, F. B. (2002). A virtual student not an ordinary Joe. The Internet and Higher Education, 5, 157-166.

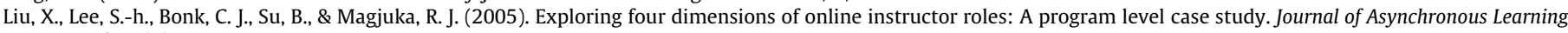
Networks, 9(4), 29-48.

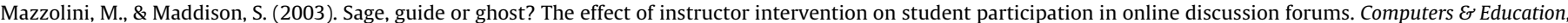
40, 237-253.

Moreno, R., \& Mayer, R. E. (2004). Personalized messages that promote science learning in virtual environments. Journal of Educational Psychology, 96(1), 165-173.

Muse, H. E. (2003). The web-based community college student: An examination of factors that lead to success and risk. Internet and Higher Education, 6, 241-261.

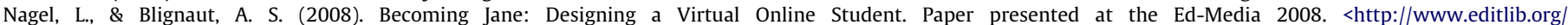
index.cfm?fuseaction=Reader.ViewAbstract\&paper_id=28983>.

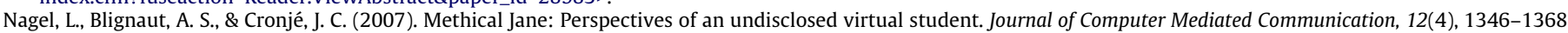

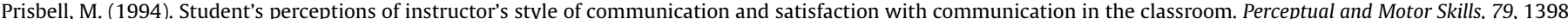

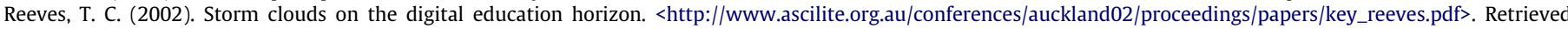
18.6.2006.

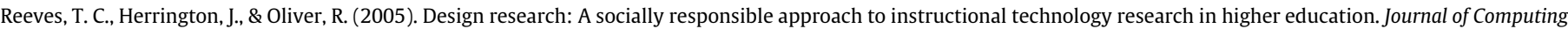
in Higher Education, 16(2), 97-116.

Reeves, B., \& Nass, C. (1996). The media equation. Cambridge, UK: Cambridge University Press.

Richardson, J. C. (2003). Examining social presence in online courses in relation to students' perceived learning and satisfaction. JALN, 7(1), 68-88

Salmon, G. (2003). E-moderating: The key to teaching and learning online (2nd ed.). London: RoutledgeFalmer.

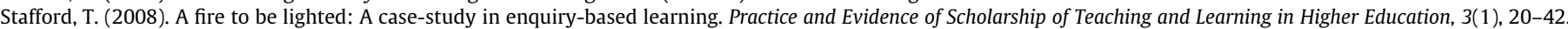

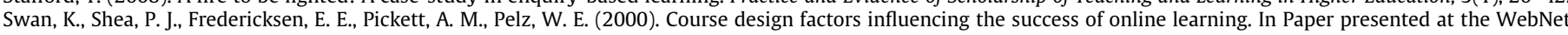
2000 world conference on the WWW and internet, San Antonio.

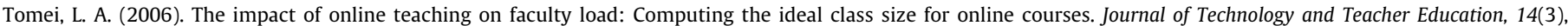
531-541.

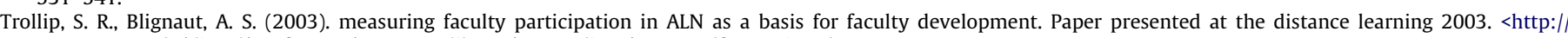
www.uwex.edu/disted/conference/Resource_library/proceedings/03 53.pdf $>$. Retrieved 27.11.2005.

Wegerif, R. (1998). The social dimension of asynchronous learning networks. Journal of Asynchronous Learning Networks, 2(1), 34-49.

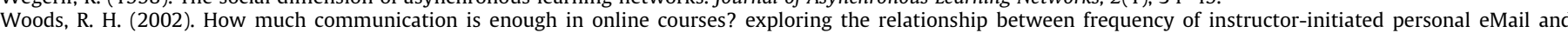
learners' perceptions of and participation in online learning. International Journal of Instructional Media, 29(4), 377-395.

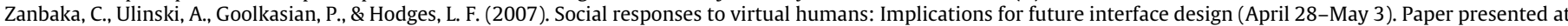
the CHI, San Jose, CA, USA. 